\title{
Is There an Instructional Framework for 21st Century Learning?
}

\author{
Shu-Shing Lee, David Hung \\ Office of Education Research, National Institute of Education, Nanyang Technological University, \\ Singapore City, Singapore \\ Email: david.hung@nie.edu.sg, shushing.lee@nie.edu.sg
}

Received June $20^{\text {th }}$, 2012; revised July $18^{\text {th }}$, 2012; accepted July $31^{\text {st }}, 2012$

\begin{abstract}
The current schooling system is great in leveling up students' literacy but it does not develop flexible understandings of concepts. We recognize that traditional instructional science model at best develop students' attitudes, skills, and knowledge (A-S-K). We propose an instructional framework for developing dispositions, attitudes, skills, and knowledge (D-A-S-K) that embraces five zones of learning: 1) zone of instruction; 2) zone of practice; 3) zone of interaction; 4) zone of tinkering; and 5) zone of meta-cognition. The proposed framework stresses that flexible learning is about the interplay between tacit and explicit knowledge. 21st century learning is about dialectical interactions between theory and practice, individuals and communities, formal and informal learning, learners and meta-cognitive brokers. The paper focuses on conceptually constructing an instructional framework for 21st century learning. We are not suggesting that our proposed framework is the only possible instructional model for the 21st century. Rather, we hope that our proposed framework invokes further discussions to examine other models for 21st century teaching and learning. Future work is needed to implement and examine the proposed framework for practical implications.
\end{abstract}

Keywords: Instructional-Learning Framework; Disposition Development; Tacit-Explicit Knowledge Interactions; Formal-Informal Learning; Meta-Cognitive Brokering

\section{Introduction}

Traditional instructional systems (IS) paradigms are fundamentally grounded on an objectivist epistemology where the focus is on codifying knowledge into reified forms and assumed that such knowledge when transmitted can be appropriated "as it is" explicitly. As long as students can reproduce these forms of explicit/reified knowledge, they are assumed to have learned (Collins, 2006; Jonassen \& Rohrer-Murphy, 1999; Karagiorgi \& Symeou, 2005; Sadler, 1989; Vrasidas, 2000).

The constructivist paradigm, on the contrary, emphasizes a different epistemology view that knowledge or knowing is in the meaning making process, and that knowledge can be reified. Reified knowledge is recognized as "versions" of narratives and these explications are always in flux (Jonassen \& RohrerMurphy, 1999; Savery \& Duffy, 2001; Vrasidas, 2000).

From an epistemological or paradigm-ic perspective, instructivists and constructivists are irreconcilable (Jonassen \& Rohrer-Murphy, 1999; Karagiorgi \& Symeou, 2005; Streibel, 1989; Vrasidas, 2000). We hope to provide a (so called) realist and pragmatist perspective to what we have observed in educational and training settings as to what works and what does not. Obviously, we recognize that what works or otherwise is value laden, but we have appropriated the 21st century literacies or dispositions as a frame of reference (Claxton \& Carr, 2004; Dede, 2010; Gardener, 2010).

In this paper we recognize that the instructional systems' model has permeated much of curricular planning and designs both in K-12 schools and in training contexts, such as the military schools. However, we have observed many transformations in these settings and what is usually imposed upon these, as instructional-objectivist may not be very accurate. On the other hand, constructivist approaches have not been pervasively adopted for the very reasons that process-oriented paradigms are non-scalable. As a consequence of our analysis of both K-12 schools and the military context (in Singapore), we attempt to conceptualize a framework that better explains or describes seemingly predominant tensions between instructional and other learning paradigms. At the same time, we recognize the urgency of the need to propose an instructional-learning framework that addresses 21st century dispositions, especially adaptability, consistent to the concept of adaptive expertise (Bransford, Brown, \& Cocking, 2000; Corte, 2007; Hatano \& Oura, 2003).

\section{Instructional Systems and the Focus on Explicit Knowledge}

We know that in traditional instructional systems' frameworks, explicit knowledge is the focus, and through task analysis, instructional objectives are derived and through these, explicit knowledge is taught (Jonassen \& Rohrer-Murphy, 1999; Karagiorgi \& Symeou, 2005; Sadler, 1989; Wilkins, 2000; Wilson, 1996; Vrasidas, 2000). Schools predominately translate these into curricular units and deliver them in instructional packages and materials. Explicit knowledge is taught, and these are usually tested through the means of exams and tests. The approach is fundamentally consistent to codifying overt knowledge, usually referred to as content, and transmitted to learners.

In typical training contexts, such as the military, where (vocational) skills are usually emphasized, learners or trainees are exposed to many out-of-classroom training exercises, and these opportunities (consistent to principles of embodiment in situations) enable the tacit dimensions of knowledge to be learned 
through personal encounters with the explicit knowledge. Militaries engage in many large scale exercises, in joint collective war-games, simulating warfare situations, and these opportunities enable trainees to apply and contextualize what they have learned theoretically (Harris, 2002; Prensky, 2001, 2003).

In other words, consistent to Polanyi's (1962) "personal knowledge" theory, useful knowledge (Whitehead, 1929) can only be applicable or productive when one has personalized that understanding (of explicit knowledge) into some form of tacit and embodied understanding-whether that knowledge was first gained explicitly through instruction or constructed socially or experientially (as in social constructivist paradigms). Whitehead (1929) alludes that much of what is learned in schools are inert or knowledge that cannot be usefully applied in real-world situations.

However, in contrast to military training contexts, significant degrees of explicit knowledge taught in K-12 schools remains "in the head" learned by heart or through rote learning pedagogical approaches. Because the content knowledge acquired through schooling thus far surpasses the opportunities to internalize knowledge or make personal through doing and experience (equivalent to out-field exercises), it is likely the case that much explicit knowledge remains as "mental" rather than "embodied”. Embodied knowledge as popularized today is probably consistent to tacit or personal knowledge (Madhavan \& Grover, 1998).

From an instructional paradigm point of view, if learners or trainees are given exposure and opportunities to learn "by doing” (Schank, 1995), we recognize that tacit knowledge can be formed and this becomes useful to the practice. Of course we are making the assumption that when learners engage in experiential learning (Kolb, 1984); the situations they encounter are as authentic as possible relative to real-world societal challenges.

Drawing implications from the above understanding, the tacit dimensions of knowing something or some domain in reality is more critical than acquiring the explicit knowledge related to that phenomenon. While paper and pencil tests serve to test what a student knows, the affordances of this form of testing mostly support mental or conceptual dimensions of knowledge. It is only through enactments in doing and in situations that both tacit and explicit knowledge can be productively tested (Polanyi, 1966). Instructional paradigms that complement both classroom and out-field training may enable attitudes, skills, and knowledge to be acquired. In this respect, schools suffer from the inability to organize for "out-field" complementarities to classroom instruction due to sheer logistical encumbrances. In military training, because of the specialized nature of skills to be learned and acquired, classroom and out-field training can be better complemented.

There is also now an advocating by educational researchers on "performance" consistent to play in theatre/drama. In a sense, learning is learning to perform within a particular stage and context similar to performances in a play (theatre). By enacting in performance, learners have to experience and develop through role-playing and first person involvement both tacit and explicit dimensions of knowledge (Chee, 2001, 2010; Gwee, Chee, \& Tan, 2010; Jan, Chee, \& Tan, 2010; Thomas \& Brown, 2009).

A key point we draw at this juncture is that while IS paradigms are usually criticized as objectivist, and tacit knowledge is not theoretically emphasized, in reality during training of specialized vocational skills, both tacit and explicit knowledge are gained through first person role-playing and enactment. In the military context, there is also an intentional stance of "knowledge management" where codification of commander's experiences is constantly required (Nonaka \& Toyama, 2003; Nonaka \& Konno, 1998; Warne, 1999; Warne, Ali, Pascoe, \& Agostino, 2001). This process enables reflection and meaning making of tacit experiences gained in "doing”. Military doctrines are constantly produced and refined over time.

\section{From Whence Does Good Learning Come from?}

From the above discussion, it is obvious that we espouse to a dialectical relationship between theory and experience. "The map is not the territory" (Korzybski, 1994: p. 58). This famous quote implies that experience in "territory" is not the "map" (or abstracted knowledge). If one engages in a "territory" experience, one relates stories and personal theories of one's experience through explicit or overt representations through language. Theories formed or get recognized by a community find their way into textbooks when many people who have similar experiences of the territory concur to the abstracted principles arising from that experience. Of course, there are also some "maps" that cannot be experienced, for example, some mathematical or physics laws that are derived from abstractions of abstractions. But fundamentally when we interpret a "map" we should recognize that a map is but one version of truth. Postmodern views recognize truth to be unknowable and all we can attain at are versions of reality (Rorty, 1999). As such, critiques of IS paradigms have their point, but that may be throwing the baby out with the bathwater.

While IS approaches advocate theory before practice as a general instructional assumption, we recognize that as long as theory is dialectically balanced with practice, and if theory can be built upon-reconstructed from personal interpretations and refined upon constantly - the development of tacit and explicit/ conceptual knowledge is gained.

The second implied dialectical relationship in the examples we described above is between the individual and collectivesocial or community. In military exercises, however constraining the in-class theory lessons may be, commanders and their soldiers engage in large scale battalion, division, and brigade level exercises. Within these structures, individuals interact with each other through many forms of media and technologies, through practice-related genres coordinate and collaborate in complex tasks, and adhere to a whole regime of rules and regulations consistent to their doctrines of military warfare. In other words, individuals engage as part of a larger community of practice (CoPs) (Wenger, McDermott, \& Snyder, 2002) within their respective roles, and there is a whole system of progression through the ranks consistent to junior to senior "ranks" within CoPs.

At this juncture, we recognize that not all IS approaches lead to individual-collective opportunities of engagement. Schools for example function historically differently from specialized vocational setups as with the military and serve probably different societal goals. Schools are generic in that they equip learners with content knowledge of the traditional disciplines, such as science, mathematics, history, etc., and there are few or no equivalent authentic and practical learning experiences that are aligned to the collective level involvements with disciple- 
nary CoPs (Brown, 2002; Brown \& Adler, 2008; Brown \& Duguid, 1996; Jonassen \& Rohrer-Murphy, 1999; Savery \& Duffy, 2001; Streibel, 1989; Vrasidas, 2000). Perhaps not with the same theoretical reasons, some high performing schools (in Singapore) have begun to forge tight collaborations with communities.

The Singapore Sports School-because of the goal of producing sportsmen and women-collaborates with Sports Councils and Federations, which in turn, links them to the larger societal community of athletes (Singapore Sports School, 2011). This principle of enactment applies also to the School of the Arts, Singapore and its linkages to the Arts community both locally and internationally (School of the Arts, 2011). Inevitably these specialized schools are linking up with communities in their sports and arts programs rather than the academic disciplines per se. The National University of Singapore (NUS) High School of Math and Science (a school tied to the NUS has links with a community of academics in the parent university (NUS High School of Math and Science, 2011). This school is the closest we have with respect to forming community links with the formal academic curriculum. However, by and large due to the IS tradition through which curricular is derived from and the need to cover increasing amounts of content, this second dialectics of individual-collective/community is found wanting.

Again, at this juncture, we caveat that IS paradigms advocate explicit knowledge and focus less on the practice of such knowledge, though not necessarily in community-collective situations. However, if we can combine or integrate IS approaches with learning by doing, and complement these with community principles of learning and engagement, we have possibilities of good learning.

\section{Societal Needs for the 21st Century}

There is also now an increasing call beyond the traditional notions of "attitudes", "skills", and "knowledge" (A-S-K) (espoused by instructional paradigms) into 21st century soft skills such as leadership, adaptability, resilience, collaboration, sociability, risk taking etc. While IS paradigms advocate A-S-K as goals of instruction, we hold to the view that IS approaches lend themselves best to S-K, where attitudes (A) are better appropriated through observations, role-modeling, and "picked up” or stolen in social contexts (Brown \& Duguid, 1996).

Policy makers, especially those in education, have a tendency to add onto the existing curriculum more needs from societywith the dominant stance of adding content. Even when these needs are values or ethics/morals inclined, filling up the "white spaces" of students who may otherwise be engaged in play, hobbies, and other forms of informal experimentations (Brown, 2005). Studies in informal learning are suggesting productive literacies, which can be developed by explorations in such contexts (Barron, 2006; Nasir \& Hand, 2008). Because it is largely difficult to control or plan for learners/students' own explorations, we usually see them as unproductive. We are raising the caution at this point that more formal content filling without the dialectical dynamics of theory-experience and individualcommunity just "makes Jack a dull boy". The corollary of quantifying what students know in international tests (such as TIMSS and PISA) may also not be necessarily holistic in developing them with tacit knowledge and experiences relevant to risk taking, experimentations, and adaptability necessary for the 21st century. But do we know whether students' informal learning experiences are productive and leading towards 21st century dispositions - if the formal is not doing it too well?

Many of these so-called 21st century skills are characterized as "soft" (Claxton \& Carr, 2004; Dede, 2010; Gardener, 2010). While there is an intuitive understanding that "soft" may thus be different from explicit content knowledge (suggesting "hard"), there is clearly a lack of a clear framework to "train" (borrowing the IS framework) these skills. Again, we appropriate the word "train" because there is the implicit assumption that these skills can be "trained". Rather, we are advocating that by the very nature these skills are soft, situations and environmental contexts where factors and conditions leading to the (higher) possibility of these soft skills can be tacitly assimilated, is probably a better framing to understanding how these soft skills can be learned. In other words, there is a greater propensity to think in the orientation that soft skills are "picked up" or "caught" in the process of learning by doing within socially rich contexts. They are by nature soft and thus oriented more towards the tacit or personal knowledge paradigm.

Moreover, when we analyze the various soft skills espoused in the 21st century literature (Claxton \& Carr, 2004; Dede, 2010; Gardener, 2010), there are those skills that lend themselves to be possibly learned within the instructional/training cum community framework, for example, collaboration and leadership within a particular practice. However, when it comes to "adaptability”, it is in our opinion that, traditional paradigms fail.

\section{Adaptability: A Disposition for the 21st Century Context}

Adaptability connotes learning by going across contextshence, not necessarily of the same specialization. The tension thus lies with the issue of how much specialization is to be learned and through what kinds of approaches, which may encourage or discourage such a disposition. For example, if learners are rote learning (from the onset of the training) even within specializations and traditional reward-punishment methods are typically adopted, we hypothesize that learners will tacitly pick up the "value" that risk taking and being adaptive is not beneficial. Hence, adaptability is first to be encouraged within specializations, and carefully encouraged to move towards across contexts explorations. Our research suggests that learners achieve flexible expertise within domains when more capable peers scaffold and model appropriate behaviors and thinking processes towards greater competencies. For learners to be adaptive and explore across contexts, they need to analyze their learning experiences in different specializations to transfer and experiment "adapted" learning strategies to enhance learning in new specializations (Hung, Lee, \& Lim, 2012; Lee, Hung, Lim, \& Shaari, in press).

Based on our research, schools' formal curricular can be complemented with Co-Curricular Activities (CCAs) to help academically weaker students perform better (Hung, Lee, \& Lim, 2012; Lee et al., in press). CCAs are typically likened to informal contexts where learners can take risks (hopefully because they would not be punished for experimenting). So while schools have adopted CCAs right from the on set of students' schooling, we should be careful not to impose too many explicit deliverables (key performance indicators) for students and link them to the formal assessments for school placement purposes. In fact, it is in our view that CCAs should be "assessed" (not in 
any high stakes fashion) for students' risk taking actions, adaptability considerations, and other forms of 21st century dispositions, which cannot be learned through the formal curricular.

It is in our hope that we can contribute to a framework where both formal and informal curricular can be complemented to holistically develop the learner in both explicit and tacit dimensions of knowledge oriented by the 21st century literacies so needed in the workforce. We recognize the role of formal curricular and the "exam" paradigm. However, our contention lies not with it, but with the extent to which it is made prominent (or high stakes) at the expense of (academically weaker) students' exposure to opportunities that develop tacit knowledge and other forms of 21st century literacies (learned in the informal CCA equivalent) on the assumption that tacit knowledge remains difficult to enact in the formal curricular.

Our research study suggests that academically weaker students can through their CCAs develop self-esteem and confidence, and these traits can be meta-cognitively transferred to the formal curriculum with the help of brokers (Hung, Lee, \& Lim, 2012; Lee et al., in press). Brokers work alongside students to compare and contrast learning experiences in CCAs with learning experiences in the formal, classroom environment. The brokers' role is to help students adjust, experiment, and transfer learning strategies across formal and informal contexts and to help students develop an "adaptive-designer" disposition to enhance students' learning in the formal curriculum. Metacognitive dialogue between brokers and learners is important because brokers probe further to aid learners articulate their cognition and catch "meta-cognitive" opportunities to help learners see complementary learning experiences between formal and informal contexts. These linkages enable more effective learning to occur and indirectly improve students' confidence levels and academic performances in the classroom context.

\section{Formal-Informal Dialectics}

As we analyzed the dispositions required, and if adaptability is consistent to the notion of adaptive expertise (Bransford, Brown, \& Cocking, 2000; Hatano \& Inagaki, 1986; Resnick, 1987; Schwartz, Brandsford, \& Sears, 2005), we reckon that the two dialectics we have identified above are insufficient. Both are within context/community/specialization and they can at best facilitate flexibility and risk taking within domains. But increasingly the call now is for adaptive rather than routine experts. By this definition, individuals are required to be crossdisciplinary.

As such we introduce a third dialectics-formal and informal.

Table 1.

Differences between formal and informal.

\begin{tabular}{ll}
\hline Formal characteristics & Informal characteristics \\
\hline Extrinsic motivation & Intrinsic motivation \\
Hierarchical & Bottom up \\
Systematized or planned & Emergent \\
Stable deliverable criteria & Community negotiable criteria \\
$\begin{array}{l}\text { High stakes responsibility usually } \\
\text { with lesser degrees for risk taking }\end{array}$ & $\begin{array}{l}\text { Allows for experimentation with } \\
\text { lower risks, usually interests } \\
\text { driven, and based on passion }\end{array}$ \\
\hline
\end{tabular}

Table 1 distinguishes the characteristics between the two.

From the characterization above, what is formal and informal largely depends on the individual's structural role involvements with that activity. For example, one of the authors is typically engaged by military agencies to do keynotes and consultancies, and to him, this setting is less formal or informal compared to his university's appointment. As such, he found himself more willing to experiment with new ideas and thoughts with the informal community.

As you can see from Table 1, informal communities such as those learners/students are involved in, for example, chess clubs, robotics, photography, and many others have characteristics for learners to experiment and develop upon their interests.

Hence, while the dialectics of theory with experience and individual with community develop A-S-K, we posit that crossboundary dispositions such as adaptability can be developed through the formal-informal dialectics.

\section{Meta-Cognition and the Role of Across-Contexts Interactions}

There are not many studies researching into the interplays between formal and informal learning (Ainsworth \& Eaton, 2010; Barron, 2006; Hall, 2009; Nasir \& Hand, 2008; Straka, 2009). In our research, we have found that meta-cognition dialogue plays a key role in forming links between formal and informal contexts. However to be effective in transferring learning experiences across contexts, brokers need to understand students' learning experiences in different contexts and then engage in metacognitive brokering for across contexts (formal-informal) comparisons. Comparisons bring forth similarities and differences between learning experiences so learning strategies in informal contexts can be adapted, transferred, and experimented to improve formal, classroom learning (Hung, Lee, \& Lim, 2012; Lee et al., in press).

Specifically, our research shows a case study of how broker leveraged on learning experiences in the bowling CCA and compared it with student's learning in mathematics (Hung, Lee, \& Lim, 2012; Lee et al., in press). Broker used the analogy of "winning strategy" from bowling competitions and applied it to develop a strategy for maximizing scores in mathematics exams. This analogy helped the student performed across contexts analysis between learning in bowling and mathematics to create a "winning strategy" for mathematics exams.

By analyzing learning incidents across contexts with the broker, the student was able to adapt and design his own learning strategy for improving grades in mathematics. He recognized that similar to training to achieve high scores in bowling competitions, he must address his weaknesses before the mathematics exam. During the exam he must read questions properly, do well in questions that he is confident of to maximize score, and leave those questions that he does not know to extra time.

Dialoguing with the broker enabled the student to capitalize on his learning experiences in the informal, bowling context and "design" his own learning strategies to attain better grades in mathematics. By working with the broker to transfer, adapt, and experiment with learning strategies across contexts, the learner developed confidence and adaptability dispositions that he could use similar approaches to enhance his learning experiences in other domains. 


\section{An Instructional Framework for Developing Dispositions, Attitudes, Skills, and Knowledge (D-A-S-K)_Combining All 3 Dialectical Interactions}

Our analysis of instruction for learning shows that holistic and authentic learning requires an instructional framework that emphasizes different dialectical relationships between learners, experience, formal and informal communities, as well as a balanced interplay between tacit and explicit knowledge. Traditional IS models can be overly linear and less emergent and dialectical. Building on from this analysis, we propose an instructional framework with five zones (see Figure 1), which is intended to be interdependent, that are mapped to the following five dimensions to develop dispositions, attitudes, skills, and knowledge:

1) Learning explicit knowledge from an instructional perspective;

2) Dialectic links between theories where individuals experience tacit knowledge through practice, and with linkages to the explicit knowledge;

3) Dialectic social interactions between individuals and communities;

4) Dialectic tinkering between learning in formal and informal communities/contexts;

5) Engaging in meta-cognitive processes to regulate and transfer learning within and across contexts.

An illustration of the proposed instructional framework for D-A-S-K is shown in Figure 1. The D-A-S-K framework is a long-term instructional model that focuses on teaching "adaptive” dispositions for life-long learning in the 21st century. The framework recognizes the importance of exams and the formal curricular for teaching conceptual knowledge in the zone of instruction. It tries to address limitations of the formal curricular for teaching 21st century dispositions by harmonizing instruction with other means, such as involving task performance in the zone of practice and dialoguing in authentic situations within the zone of social interaction. The instructional framework for D-A-S-K creates numerous opportunities for reinforcing holistic learning through different ways, especially for academically weaker students, by emphasizing the development of tacit knowledge and 21st century dispositions, like adaptability.

It must be emphasized that the different zones in the framework are non-linear or not of equal emphasis. However, all zones need to operate smoothly to provide varying learning experiences that balance tacit and explicit aspects of knowing.

As shown in Figure 1, the proposed framework for D-A-S-K nurtures tacit and explicit knowledge coupled with 21st century dispositions through a formal-informal learning trajectory. The dual directional arrow shows a continuum of learning and instruction that emphasizes the interplay between formal-informal contexts and explicit-tacit knowledge. On the extreme left end, zone of instruction focuses on teaching explicit knowledge in formal, classroom environments. Towards the right end, learning moves into informal contexts where tacit knowledge is emphasized.

Meta-cognitive brokering (see zone of meta-cognition, Figure 1) manages learning in all zones; enabling learners to be adaptive within contexts and handling cross boundary situations. Specifically, the zones of instruction, practice, and interaction form an entity that focuses on learning D-A-S-K within contexts while learning that embraces all zones on the left side of Figure 1 relates to learning that crosses contexts.

In the paragraphs below, each zone in the proposed framework is discussed with examples from the schooling and military contexts.

\section{Zone of Instruction—“Learning by Heart”}

Zone of instruction is aligned with the IS model that mainstream schools use to teach students content knowledge. In this zone, there is an objective relationship between learner and theory. The emphasis is on the objectivist epistemology where teacher is the sage. Task analysis is used to derive curricular units and deliverables. This allows teachers to determine the types of codified knowledge to transmit to students without focusing on context of use. The general assumption is teachers should advocate in-depth understandings of the theory before moving on to practice.

Paper and pencil tests are predominantly used to evaluate students' performance. Students are thought to have learned if they reproduce conceptual dimensions of knowledge that are similar to that of the teacher. By not focusing on practice, knowledge acquired remains inflexible and inert as a mental state.

The zone of instruction is particularly useful for learning foundational content knowledge, such as the multiplication table or the periodic table for chemistry. There is now a body of literature that suggests that learning by heart is efficacious and that such traditional pedagogies can be useful (Chan, 2008;

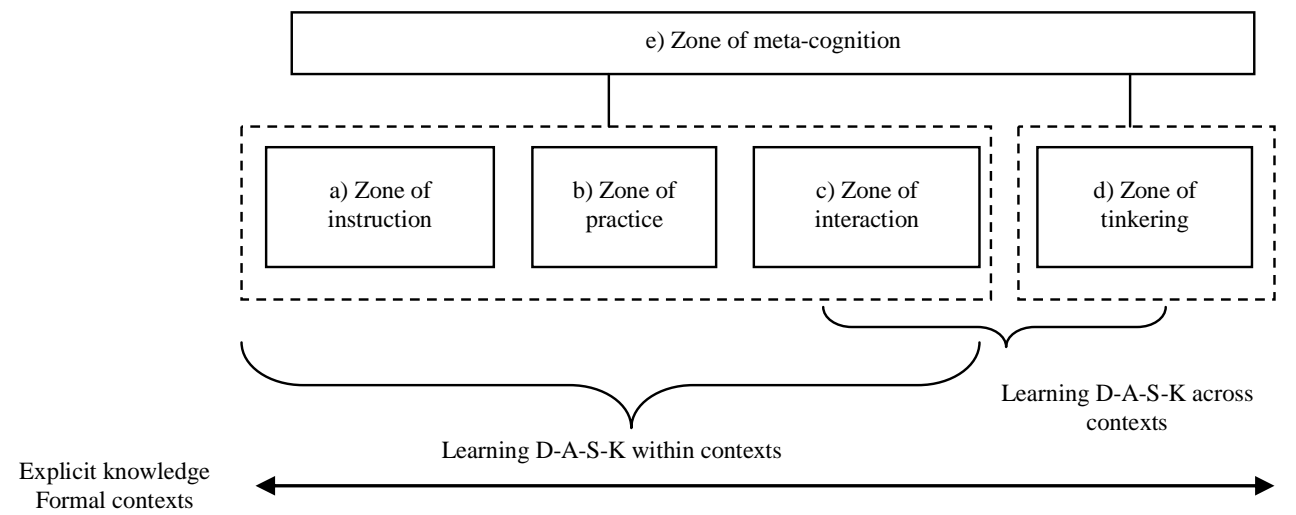

Figure 1.

Learning through an instructional framework for D-A-S-K. 
Kennedy, 2002; Lee, 2009; Yang, Zheng, \& Li, 2006; Yusuf, 2010).

\section{Zone of Practice-“Learning by Performance”}

"Learning by performance" involves instruction that recognizes learning as a dialectic relationship between theory and experience. This is an improvement of the traditional IS model by harnessing practice or field training. Through real-life enactments of codified knowledge to perform authentic tasks, conceptual knowledge is restructured with personal interpretations to include tacit dimensions. This leads to a personalized understanding of concepts that embraces both explicit and tacit knowledge.

Teaching and learning in the zone of practice is similar to performance-based learning. Students through first person engagements in practice acquire authentic learning experiences, thus, building tacit knowledge onto conceptual understandings (Chee, 2001, 2010).

Assessment of learning in this zone does not focus solely on exams. It stresses authentic performances in real-life scenarios and tries to assess learning by understanding if students can solve authentic problems.

In schools, like the Institute of Technical Education in Singapore, vocational and practical skills are emphasized in its teaching practices. Assessments of learning do not just focus on traditional pencil and paper exams but also stress practicum exams. For example, students enrolled in the hairdressing course are assessed based on how they understand clients' requests and whether they can perform hair services, like perming and dyeing.

Drawing examples from the military, foundation schools can be aligned to both zones of instruction and practice. In the military context, it is not good enough for soldiers to know explicit knowledge (such as, parts of the rifle) but they must also know how to use the knowledge to engage in warfare and strategies (for example, they must know how to fire the rifle and load it with bullets).

\section{Zone of Interaction—-Learning by Social Interaction"}

Zone of interaction relates to teaching that involves dialectical social interactions between learners and a community. The collective level social interactions allow experiential knowledge to be formed by talking to members and being enculturated to practitioners' ways of thinking. Experiential knowledge is intrinsically formed through a bodily experience of the domain. The experience is about being exposed to the context's affordances, being embodied in the community's practices, and becoming a member of the community. Experiential knowledge includes tacit and explicit knowledge plus the collective, social dimensions of knowledge that are formed by interacting with the community.

Currently, we see some schools in Singapore trying to connect students with communities of practitioners. For example, The Singapore Sports School collaborates with national sports councils and federations to come out with a training schedule that does not disrupt athletes' schooling schedule. The NUS High School of Math and Science gets academics from its parent university (NUS) to mentor students' projects that require research skills.
In the military environment, zone of interaction is aligned with specialized units (for example, infantry or artillery units) and advanced schools. In specialized units, schooled soldiers engage in performative actions as members of a community of military practice. Soldiers go to advanced schools to dialogue with soldiers from other specialized units. They form larger communities within the military environment to share experiences, and update their doctrines of practice and theories.

\section{Zone of Tinkering_- “Learning by Playing” in Informal Communities}

The above three zones are useful for teaching D-A-S-K within contexts. Zone of instruction and practice stress more on skills (S) and knowledge (K) while zone of interaction is better at teaching dispositions (D) and attitudes (A) because of its involvement in communities of practice. Increasingly, D-A-S-K within contexts is insufficient to deal with problems in the 21st century milieu where fluidness and adaptability across domains are commonplace.

The instructional framework for D-A-S-K advocates that dispositions, such as adaptability across contexts, should be nurtured through a dialectical relationship between formal and informal contexts. This naturally leads to the zone of tinkering where learners learn by "playing" in different informal communities.

What is defined as formal or informal very much depends on the structure and learners' role involvement within contexts. In schools, formal learning occurs in classrooms where students learn traditional disciplines like languages, humanities, mathematics, and science. CCAs are seen as learning in informal contexts because there are no formal assessments and students engage in domains that interest them.

The informal learning environment provides affordances that offer rich opportunities for risk-taking and experimenting with theories. The informal environment allows dispositions, like adaptability across contexts, to be "pick up" because learners are involved in various para-communities where experimental learning occurs and "trial and error" strategies are used.

For example, in the schooling environment, informal learning in the athletics CCA teaches students to adapt strategies according to their strengths and weaknesses, to get good timings, and be resilient when setbacks occur. In contrast, informal learning in the military environment involves soldiers participating in professional development that is outside of the military context but relates to their interests. This creates a path for second career after retirement. Professional development in informal, para-communities is important in the military context because soldiers tend to retire at an earlier age.

\section{Zone of Meta-Cognition-“Learning by Comparing and Contrasting” between Contexts}

The zone of meta-cognition is a "systems-level" zone that raises above all the other zones. Teachers here act as brokersengaging in learners' meta-cognitive processes to manage and link learning experiences both within and across contexts. Teacher brokers form linkages by being familiar with learners' involvement in multiple communities and contexts (such as, CCAs) to complement formal, classroom learning. Teacher brokers need not be content experts in all domains. They engage in meta-cognitive dialogue with learners by comparing 
and contrasting experiences to transfer and adapt learning strategies within and across contexts.

Brokering experiences within contexts involve learners reflecting and articulating their learning experiences in the zones of instruction, practice, and interaction. Teacher brokers probe learners to understand their strengths and weaknesses and design strategies to address these issues. On the other hand, managing learning across zones relates to teacher brokers dialoguing with students to transfer experiences across contexts, such as between classroom and CCA contexts. By analyzing similarities between contexts, teacher brokers work with students to adapt and experiment learning strategies from informal contexts (such as, bowling CCA) to impact students' learning in formal environments (such as, learning mathematics in school). Acculturation is thus established where traits from one context are borrowed or modified for another context.

For instance, teacher brokers may transfer the "calibration" analogy used in bowling to mathematics exams. In bowling, “calibration" relates to regulating one's hand swing to the outside lane to ensure consistency in competitions. For mathematics, "calibration" means students understand different methods of answering word problems for each topic. They then calibrate answers accordingly to achieve better grades.

Table 2 summarizes key tenets of the proposed instructional framework for D-A-S-K.

\section{Discussion and Implications A Flexible and Personalized Way of Learning}

The current schooling system is a great system but we must not see learning just from the traditional perspective. The proposed instructional framework for D-A-S-K is a more holistic, long-term model that attempts to develop "adaptive” disposi- tions for the 21st century. The framework understands the IS model's efficiency in leveling up students' literacy. However, schools have removed the entire process through which holistic and embodied learning occurs. An over emphasis on instruction and explicit knowledge leads to less learning about tacit knowledge through tinkering, exploring, and problem solving.

In the IS paradigm, there is often huge lag time between instruction and experience (Cope, 2005). By the time students use the knowledge to solve problems the knowledge is forgotten. Knowledge without first person experiences remains inert and irrelevant. Learning in schools is de-contextualized because knowledge is taught without demonstrating its use (Collins, 2006). This kind of learning has immense consequences. When students see learning as irrelevant, they lose motivation. It kills their love for life-long learning, which is vital for the 21st century.

The proposed instructional framework for D-A-S-K tries to address constraints in the IS paradigm by harmonizing instructtion with other ways of attaining tacit knowledge through performance, dialogue, dialectics across contexts, and meta-cognitive brokering. The proposed instructional framework, thus, reinforces holistic learning by creating opportunities for flexible and personalized learning on two levels (Hargreaves \& Shirley, 2009).

Firstly, the different zones proposed in the framework attempt to provide supportive learning structures for different students. Students who do not benefit from instruction are afforded opportunities to reinforce conceptual understandings by enacting and interacting with communities of practitioners. Students who excel in explicit knowledge can develop personalized understandings by solving problems and affiliating themselves with communities. The purposed instructional framework, therefore, enables both academically strong and weak

Table 2.

Key tenets of an instructional framework for D-A-S-K.

\begin{tabular}{|c|c|}
\hline \multicolumn{2}{|r|}{ An Instructional Framework for D-A-S-K } \\
\hline Zones & Key Tenets \\
\hline Zone of instruction & $\begin{array}{l}\text { - Traditional IS model } \\
\text { - } \quad \text { Teacher is the sage } \\
\text { - } \quad \text { Focuses on acquiring conceptual knowledge without context } \\
\text { - } \quad \text { Learning is measured by reproducing conceptual knowledge (i.e. paper and pencil exam) }\end{array}$ \\
\hline Zone of practice & $\begin{array}{l}\text { - Traditional instructional system + in-field practice } \\
\text { - } \quad \text { Personal understanding of explicit knowledge through embodiment in authentic tasks and problems } \\
\text { - } \quad \text { Focuses on codified knowledge + practical experience = personal, tacit knowledge } \\
\text { - Assessment of learning = paper and pencil exam + practicum }\end{array}$ \\
\hline Zone of interaction & $\begin{array}{l}\text { - Learning by embodying in practices, social interactions, and collective knowledge of communities of practitioners } \\
\text { - Experiential knowledge is constructed through interacting with members and embracing thinking processes of } \\
\text { practitioners } \\
\text { - Experiential knowledge = Tacit knowledge + explicit knowledge + collective social knowledge }\end{array}$ \\
\hline Zone of tinkering & $\begin{array}{l}\text { - Learning by “playing” in informal community } \\
\text { - Formal or informal community dependant on learner's role involvement } \\
\text { - Informal communities provide affordances to “pick up” 21st century dispositions, like risk-taking, experimentation, and } \\
\text { adaptability }\end{array}$ \\
\hline Zone of meta-cognition & $\begin{array}{l}\text { - A "systems-level" zone that links and manages learning in the different zones through metacognitive brokering } \\
\text { - Teacher brokers dialogue with learners to compare and contrast learning experiences between formal and informal } \\
\text { contexts } \\
\text { - Teacher brokers probe learners to articulate their cognition and reflect their strengths and weaknesses } \\
\text { - Teacher brokers need not be content experts but act as facilitators to enable across context learning experiences }\end{array}$ \\
\hline
\end{tabular}


students to experience holistic learning because learning is addressed in a different way, emphasizing dialectics between tacit and explicit knowledge.

21st century learning is all about dialectics. The dialectics of theory and practice enable enactments of explicit knowledge to shape personalized understandings. The dialectics of individuals with communities create experiential knowledge through interactions with practitioners. Students do not just learn about the discipline but they learn how to practice that discipline. The formal-informal dialectics facilitate tinkering, exploring, and experimenting to develop cross-boundary dispositions, like adaptability.

Secondly, the proposed instructional framework supports personalized learning because there is flexibility in terms of how learning may evolve from tacit or explicit knowledge. The proposed framework does not dictate the order of how different kinds of knowledge are acquired. Learning does not follow the IS approach where students focus first on content and then work on enacting that explicit knowledge in authentic situations. Students can learn within the proposed five zones in non-linear ways. The order of learning is less important. Instead, learning as a process should be student-driven and flexible-moving towards a cyclical model that adapts to students' goals and provokes their thinking.

Smooth transitions and strong links between the proposed zones are important so learning does not appear disorganized. The zone of meta-cognition, thus, plays an essential, macro role. It is the "executive control tower" of the learning process. Teachers engage in meta-cognitive dialoguing to understand students' learning experiences in different zones and help students form adaptive understandings. Meta-cognitive brokering also occurs across formal and informal contexts where teachers dialogue with students to transfer and re-contextualize learning strategies across contexts.

The key emphasis in the proposed instructional framework is that there must be interplay between tacit and explicit knowledge to engage students in experiential learning (Kolb, 1984). This kind of learning is contextualized and authentic. When students appreciate how to use knowledge, they develop motivation. Learning becomes relevant and active not passive.

\section{Using Technology to Achieve 21st Century Learning}

Technology greatly facilitates flexible and holistic learning (Collins, 2006). Technology can be used to augment classrooms so that all fives zones proposed are practiced within the same curricular time as what students are currently doing. For instance, content that is traditionally taught through face-to-face instruction can be made available online so students retrieve them on a "need to know" basis. Online worlds, such as Quest Atlantis and Second Life (Barab, Thomas, Dodge, Carteaux, \& Tuzun, 2005; Brown \& Adler, 2008), may address logistical constraints in classroom contexts by incorporating more practice opportunities after classroom hours. Students can enact conceptual knowledge in virtual environments or engage in inquiry to develop tacit and explicit knowledge from first person perspectives. Technology, hence, creates opportunities for social collaborations and interactions in online worlds and communities without sacrificing classroom time (Karagiorgi \& Symeou, 2005).

In this manner, there is perhaps no need to teach all the theory first and then practice knowledge in authentic situations.
Learning should be adaptive occurring in a cyclical, spiral manner that is student-driven and on-demand. Learning is a hybrid of core curricula coupled with opportunities to branch off to other interests in different contexts. (Brown, 2005). Technology is invested to augment classrooms. Through technology, learning in the proposed zones becomes flexible and personalized because it is not constrained by time and place. Time may be freed to encourage learners to explore interests in informal communities. Interacting with informal communities is key to holistic learning because it opens up learners' perspectives and encourage across context interactions. Informal learning situations afford opportunities for learners to develop adaptability skills because it provides embodied learning experiences for learners to compare, contrast, and re-contextualize learning strategies for the formal classroom context.

Learning, thus, becomes cyclical focusing on instruction, practicum, and reflection that is embedded across contexts. Teachers are not sages. They become meta-cognitive brokers. Classroom time is used less for instruction. Face-to-face time is used to engage students in more discussions and dialogues with teachers to address problems and weaknesses. Teachers apply meta-cognitive brokering to ensure that students understand how learning in the proposed zones gel together to form adaptive understandings about domains. Teachers encourage students to share their learning experiences in different contexts so that they may help students form links and transfer learning strategies across formal-informal contexts. In this process of meta-cognitive brokering, students may begin to appropriate dispositions of adaptability as they transfer and experiment with learning strategies across formal-informal contexts.

Fundamentally, the teachers' role has evolved to be less intrusive. It is more about guidance and facilitation on the fly (Brown, 2005). Classroom instruction sets the context and guides the learning activity. Teachers do not impose restrictions on how the learning process should be like in the IS model. Learning is now driven by students' feedback about achievements and challenges in their learning experiences.

\section{Conclusion}

In this paper, the efficiency of the IS model is recognized while incorporating four additional dimensions to advocate an embodied way of learning. An instructional framework for $\mathrm{D}-\mathrm{A}-\mathrm{S}-\mathrm{K}$ is proposed and five dimensions of learning are mapped to establish five zones for 21 st century learning. The five zones are: 1) zone of instruction; 2) zone of practice; 3) zone of interaction; 4) zone of tinkering; and 5) zone of metacognition.

In our view, IS models at best enable attitudes, skills, and knowledge to be developed. The framework, which we have proposed further elaborates and enhances IS models with a dispositional dimension and we are explicit to emphasize the inter-relations that are necessary across the five zones. We have also emphasized the dialectical nature of tacit-explicit knowledge, individual-community, and formal-informal dimensions which are lacking or non-holistic in existing IS and training models. With the inclusion of meta-cognition to make sense of the learning experienced by learner(s) across these five zones, we believe our non-linear framework describes a process of learning and instruction, which is more consistent to the needs of the 21st century.

This paper has focused on constructing an instructional 
framework for 21st century learning. We are not suggesting that our proposed framework is the only possible avenue to achieve learning and instruction for the 21st century. Rather, we hope that our proposed framework sparks further discussions to understand how IS models can be value-added by leveraging other possibilities, like learning within communities and learning in informal contexts, to enrich students' learning experiences and prepare them to be adaptive individuals for the 21st century. We understand that the implementation of any instructional framework involves a substantial time frame and complex issues, like supporting policies, leadership, and accountability to stakeholders. Future work is needed to implement and examine the proposed framework for practical implications.

\section{REFERENCES}

Ainsworth, H. L., \& Eaton, S. E. (2010). Formal, non-formal and informal learning in the sciences. Calgary: Onate Press.

Barab, S., Thomas, M., Dodge, T., Carteaux, R., \& Tuzun, H. (2005). Making learning fun: Quest Atlantis, a game without guns. Educational Technology Research \& Development, 53, 86-107. doi:10.1007/BF02504859

Barron, B. (2006). Interest and self-sustained learning as catalysts of development: A learning ecology perspective. Human Development, 49, 193-224. doi:10.1159/000094368

Bransford, J. D., Brown, A. L., \& Cocking, R. R. (2000). How people learn: Brain, mind, experience, and school: Expanded edition. Washington: National Academy Press.

Brown, J. S. (2002). Learning in the digital age. In M. Devlin, R. Larson, \& J. Meyerson (Eds.), The Internet and the university: 2001 forum (pp. 65-91). Boulder, CO: EDUCAUSE Publications.

Brown, J. S. (2005). New learning environments for the 21st century. URL (last checked 3 August 2012).

http://www.johnseelybrown.com/newlearning.pdf/

Brown, J. S., \& Alder, R. P. (2008). Minds on fire: Open education, the long tail, and learning 2.0. EDUCAUSE Review, 17-32.

Brown, J. S., \& Duguid, P. (1996). Stolen knowledge. In H. McLellan (Ed.), Educational technology publications (pp. 47-56). Bergen, NJ: Englewood Cliffs.

Chan, C. K. K. (2008). Pedagogical transformation and knowledgebuilding for the Chinese learner. Evaluation \& Research in Education, 21, 235-251. doi:10.1080/09500790802485245

Chee, Y. S. (2001). Networked virtual environments for collaborative learning. Proceedings of ICCE/School Net 2001-9th International Conference on Computers in Education, Seoul, November 2011, 311.

Chee, Y. S. (2010). Game-based learning as performance: The case of legends of Alkhimia. In B. Meyer (Ed.), Proceedings of the 4th European Conference on Games Based Learning (pp. 47-54). Reading: Academic Publishing.

Claxton, G., \& Carr, M. (2004). A framework for teaching learning: The dynamics of disposition. Early Years, 24, 87-97. doi:10.1080/09575140320001790898

Collins, A. (2006). Cognitive apprenticeship. In R. K. Sawyer (Ed.), The Cambridge handbook of the learning sciences (pp. 47-60). Cambridge: Cambridge University Press.

Cope, N. (2005). Apprenticeship reinvented: Cognition, discourse and implications for academic literacy. Prospect, 20, 42-62.

Corte, E. D. (2007). Learning from instruction: The case of mathematics. Learning Inquiry, 1, 19-30. doi:10.1007/s11519-007-0002-4

Dede, C. (2010). Comparing frameworks for 21st century skills. In J. Bellance, \& R. Brandt (Eds.), 21st century skills: Rethinking how students learn (pp. 51-76). Bloomington, IN: Solution Tree Press.

Gardener, H. (2010). Five minds for the future. In J. Bellance, \& R. Brandt (Eds.), 21st century skills: Rethinking how students learn (pp. 9-31). Bloomington, IN: Solution Tree Press.

Gwee, S, Chee, Y. S., \& Tan, E. M. (2010). Assessment of student outcomes of mobile game-based learning. In S. L. Wong, et al. (Eds.),
Proceedings of the 18th International Conference on Computers in Education (pp. 412-416). Putrajaya: Asia-Pacific Society for Computers in Education.

Hall, R. (2009). Towards a fusion of formal and informal learning environments: The impact of the Read/Write Web. Electronic Journal of E-Learning, 7, 29-40.

Harris, P. (2002). How the US military is reinventing learning. Learning circuits: American society for training and development. URL (last checked 3 August 2012). http://www.astd.org/LC/2002/1102_harris.htm

Hatano, G., \& Inagaki, K. (1986). Two courses of expertise. In H. Stevenson, H. Azuma, \& K. Hakuta (Eds.), Children development and education in Japan (pp. 262-272). New York: Freeman.

Hatano, G., \& Oura, Y. (2003). Commentary: Reconceptualizing school learning using insight from expertise. Educational Researcher, 32, 26-29. doi:10.3102/0013189X032008026

Hung, D., Lee, S. S., \& Lim, K. Y. T. (2012). Teachers as brokers: Bridging formal and informal learning in the 21st century. KEDI Journal of Educational Policy, 9, 69-87.

Jan, M., Chee, Y. S., \& Tan, E. M. (2010). Changing science classroom discourse toward doing science: The design of a game-based learning curriculum. In S. L. Wong et al. (Eds.), Proceedings of the 18th International Conference on Computers in Education (pp. 543-547). Putrajaya: Asia-Pacific Society for Computers in Education.

Jonassen, D. H., \& Rohrer-Murphy, L. (1999). Activity theory as a framework for designing constructivist learning environment. Educational Technology, Research and Development, 47, 61-79. doi:10.1007/BF02299477

Karagiorgi, Y., \& Symeou, L. (2005). Translating constructivism into instructional design: Potential and limitations. Educational Technology \& Society, 8, 17-27.

Kennedy, P. (2002). Learning cultures and learning styles: Myth-understandings about adult (Hong Kong) Chinese learners. International Journal of Lifelong education, 21, 430-445. doi:10.1080/02601370210156745

Kolb, D. A. (1984). Experiential learning: Experience as the source of learning and development. Englewood Cliffs, NJ: Prentice Hall.

Korzybski, A. (1994). Science and sanity: An introduction to nonAristotelian systems and general semantics (5th ed.). New York: Institute of General Semantics.

Lee, S. S., Hung, D., Lim, K. Y. T., \& Shaari, I. (in press). Learning adaptivity across contexts. In D. Hung, K. Y. T. Lim, \& S. S. Lee (Eds.), Adaptivity as a transformative disposition for learning in the 21st century. Dordrecht: Springer.

Lee, W. O. (2009). Conceptualizing citizenship and citizenship education: A trajectory of exploring Asian perspectives. URL (last checked 3 August 2012).

http://www.ied.edu.uk/cplectures/resource/prof_lee_wing_on_09062 3_1_.pdf

Madhavan, R., \& Grover, R. (1998). From embedded knowledge to embodied knowledge: New product development as knowledge management. Journal of Marketing, 62, 1-12. doi:10.2307/1252283

Nasir, N. S., \& Hand, V. (2008). From the court to the classroom: Opportunities for engagement, learning, and identity in baseketball and classroom mathematics. Journal of the Learning Sciences, 17, 143179. doi:10.1080/10508400801986108

Nonaka, I., \& Nonno, N. (1998). The concept of "ba": Building a foundation for knowledge creation. California Management Review, 40, 40-54.

Nonaka, I., \& Toyama, R. (2003). The knowledge-creating theory revisited: Knowledge creation as a synthesizing process. Knowledge Management Research \& Practice, 1, 2-10. doi:10.1057/palgrave.kmrp.8500001

NUS High School of Math and Science (2011). NUS High School. URL (last checked 3 August 2012). http://www.highsch.nus.edu.sg/

Polanyi, M. (1962). Personal knowledge: Towards a post-critical philosophy. Chicago, IL: University of Chicago.

Polanyi, M. (1966). The tacit dimension. New York: Doubleday \& Company, Inc.

Prensky, M. (2001). Digital game-based learning. New York: McGrawHill. 
Prensky, M. (2003). Digital game-based learning. ACM Computers in Entertainment, 1, 1-4. doi:10.1145/950566.950596

Resnick, L. (1987). Learning in school and out. Educational Researcher, 16, 3-21. doi:10.2307/1175725

Rorty, R. (1999). Philosophy and social hope. London: Penguin Books.

Sadler, D. R. (1989). Formative assessment and the design of instructional systems. Instructional Science, 18, 119-144.

doi:10.1007/BF00117714

Savery, J. R., \& Duffy, T. M. (2001). Problem based learning: An instructional model and its constructivist framework. Technical Report, Bloomington, IN: Indiana University.

Schank, R. C. (1995). What we learn when we learn by doing. Technical Report, Chicago, IL: Northwestern University.

School of the Arts Singapore (2011). School of the arts Singapore. URL (last checked). http://www.sota.edu.sg/

Schwartz, D., Bransford, J., \& Sears, D. (2005). Efficiency and innovation in transfer. In J. Mestre (Ed.), Transfer of learning from a modern multidisciplinary perspective (pp. 1-51). Greenwich, CT: Information Age Publishing.

Singapore Sports School (2011). Singapore sports school. URL (last checked). http://www.sportsschool.edu.sg/index.aspx

Straka, G. A. (2009). Informal and implicit learning: Concepts, communalities and differences. European Journal of Vocational Training, $48,132-145$.

Streibel, M. J. (1989). Instructional plans and situated learning: The challenge of Suchman's theory of situated action for instructional designers and instructional systems. Journal of Visual Literacy, 9, 8-34.

Thomas, D., \& Brown, J. B. (2009). Why virtual worlds can matter. International Journal of Learning and Media, 1, 37-49. doi:10.1162/ijlm.2009.0008
Vrasidas, C. (2000). Constructivism versus objectivism: Implications for interaction, course design, and evaluation in distance education. International Journal of Educational Telecommunications, 4, 339362.

Warne, L. (1999). Understanding organizational learning in military headquarters: Findings from a pilot study. Proceedings of the 10th Australasian Conference on Information Systems, Wellington, 1-3 November 1999, 1144-1158.

Warne, L., Ali, I., Pascoe, C., \& Agostino, K. (2001). A holistic approach to knowledge management and social learning: Lessons learnt from military headquarters. Australasian Journal of Information Systems, 9, 127-142.

Wenger, E., McDermott, R., \& Snyder, W. M. (2002). A guide to managing knowledge: Cultivating communities of practice. Boston, MA Harvard Business School Press.

Wilkins, J. L. M. (2000). Preparing for the 21st century: The status of quantitative literacy in the United States. School of Science and Mathematics, 100, 405-418. doi:10.1111/j.1949-8594.2000.tb17329.x

Wilson, B. (1996). Dynamic learning communities: An alternative to designed instruction. In M. Simonson (Ed.), Proceedings of Selected Research and Development Presentations (pp. 800-809). Washington DC: Association for Educational Communications and Technology. Whitehead, A. N. (1929). The aims of education. New York: MacMillan.

Yang, B., Zheng, W., \& Li, M. (2006). Confucian view of learning and implications for developing human resources. Advances in Developing Human Resources, 8, 346-354. doi:10.1177/1523422306288427

Yusuf, M. (2010). Memorization as a learning style: A balance of approach to academic excellence. OIDA International Journal of Sustainable Development, 1, 49-58. 